\title{
ANÁLISE DA EVOLUÇÃO DOS INDICADORES DE DESENVOLVIMENTO ECONÔMICO NOS ESTADOS BRASILEIROS: UMA ABORDAGEM ESPACIAL (1995-2014)
}

Cristiéle de Almeida Vieira ${ }^{1}$ Sibele Vasconcelos de Oliveira ${ }^{2}$

Resumo: O Brasil é caracterizado não somente pela vasta e diversa extensão territorial, mas também pelas desigualdades socioeconômicas. Constituídas por um processo histórico, as disparidades de renda e de acesso a serviços básicos representam fontes expressivas de privação à população brasileira. Destarte, o presente estudo tem por objetivo avaliar a evolução dos indicadores de desenvolvimento dos estados brasileiros no período pós-implementação do Plano Real. Para tanto, operou-se com ferramentais de estatística descritiva para perceber como se comportaram no tempo as variáveis associadas às dimensões renda, capital físico, capital humano e desigualdade. Dentre os principais resultados, podese destacar a grande disparidade entre as regiões brasileiras, que são ainda maiores quando consideradas as realidades para os estados.

Palavras-chave: Desigualdades sociais. Desenvolvimento regional. Políticas públicas.

\section{ANALYSIS OF THE EVOLUTION OF ECONOMIC DEVELOPMENT INDICATORS IN THE BRAZILIAN STATES: A SPACE APPROACH (1995-2014)}

\begin{abstract}
Brazil is characterized not only by the vast and diverse territorial extension, but by socioeconomic inequalities. Constituted by a historical process, income disparities and access to basic services represent significant sources of deprivation to the Brazilian population. Thus, the present study aims to evaluate the evolution of the development indicators of the Brazilian states in the postimplementation period of the Real Plan. We used descriptive statistical tools to understand how the variables associated with the income, physical capital, human capital and inequality dimensions behaved in time. Among the main results, we can highlight the great disparity between the Brazilian regions, which are even greater when considering the realities for the states.
\end{abstract}

Keywords: Social inequality. Regional development. Public policy.

\section{ANÁLISIS DE LA EVOLUCIÓN DE LOS INDICADORES DE DESARROLLO ECONÓMICO EN LOS ESTADOS BRASILEÑOS: UN ENFOQUE ESPACIAL (1995-2014)}

Resumen: Brasil se caracteriza no sólo por la amplia y diversa extensión territorial, sino también por las desigualdades socioeconômicas. Constituidas por un proceso histórico, las disparidades de renta y de acceso a servicios básicos representan fuentes expresivas de privación a la población brasileña. De este modo, el presente

\footnotetext{
${ }^{1}$ Universidade Estadual de Maringá, Pós-Graduação em Economia, Maringá, Brasil, crissavieira@gmail.com, https://orcid.org/0000-0002-1825-0097

${ }^{2}$ Universidade Federal de Santa Maria, Departamento de Economia e Relações Internacionais, Santa Maria, Brasil, sibele.oliveira@ufsm.br, https://orcid.org/0000-0002-1825-0097
} 
estudio tiene por objetivo evaluar la evolución de los indicadores de desarrollo de los estados brasileños en el período post-implementación del Plan Real. En el caso de que se trate de una variable asociada con el ingreso, el capital físico, la capital de capital y la desigualdad de los servicios en tiempo. Para ello, se operó con herramientas de estadística descriptiva para percibir cómo se comportaron en el tiempo las variables asociadas a las dimensiones renta, capital físico, capital humano y desigualdad. Entre los principales resultados, cabe destacar la gran disparidad entre las regiones brasileñas, que son aún mayores cuando se consideran las realidades para los estados.

Palabras clave: Desigualdad social. Desarrollo regiona. Política pública.

\section{Introdução}

O conceito de desenvolvimento, embora amplamente discutido, não possui uma definição universal na literatura especializada. Em especial, no período que antecede à Segunda Guerra Mundial, este tema costumava ficar à margem das discussões políticas e acadêmicas, uma vez que a era do crescimento acelerado e da acumulação de capital dominava. Sobretudo, as consequências do período pósguerra perante parcela expressiva da população mundial foram intensas, com a observação de altos níveis de desemprego e miséria, fazendo com que os estudos sobre desenvolvimento ganhassem ênfase econômica e social (SUNKEL; PAZ, 1998; BRESSER-PEREIRA, 2014; NIEDERLE; RADOMSKY, 2016).

As negociações que objetivaram o estabelecimento de organismos multilaterais marcaram o comprometimento global em nome da estabilidade econômica pró-crescimento. Um exemplo é a criação da Organização das Nações Unidas (ONU), em 1945, composta por 51 países e que tinha como função promover o crescimento concomitantemente ao aumento da qualidade de vida das pessoas. Ou seja, neste período inicia-se o movimento de uma governança global para o novo contexto político do pós-guerra que fosse responsável pela formulação de acordos internacionais (OLIVEIRA, 2002; NIEDERLE; RADOMSKY, 2016).

Assim, pode-se argumentar que esta busca por novas respostas e a tentativa constante dos países de superar o estado de miséria e desemprego deixado pela guerra, fez com que intensificasse os estudos sobre "o que é desenvolvimento" e "como alcançar o desenvolvimento". Grosso modo, surgiram duas principais correntes de pensamento. A primeira, dita modelo neoclássico, em que se afirmava que o crescimento geraria automaticamente o desenvolvimento. Nesta perspectiva, cita-se o trabalho de Rostow (1960), que afirmava que "The economic progress is a 
necessary condition for some other purpose, judged to be good: be it national dignity, private profit, the general welfare, or a better life for the children".

Ainda, mencionam-se as correntes de pensamento denominadas cepalina e marxista, que enfatizavam que o crescimento não é via suficiente para 0 desenvolvimento (SOUZA, 2012; VIEIRA; ALMEIDA; OLIVEIRA; PAULI, 2017). Para Celso Furtado (1994), a industrialização embora variável importante, não é a única e nem mesmo a variável central na trajetória do desenvolvimento, principalmente tratando-se de países periféricos, como é o caso do Brasil. É necessário, segundo o autor, analisar as questões sociais e culturais do país.

Vale mencionar as contribuições como de Amartya Sen (2010) para os debates sobre 0 desenvolvimento. Segundo 0 autor, 0 fenômeno do desenvolvimento ocorre quando há expansão das liberdades, sociais, econômicas e políticas. Assim, as estratégias de desenvolvimento devem buscar a erradicação das principais fontes de privação, como pobreza e tirania (SEN, 2010).

Diante do exposto, a problemática que permeia este é: Como se deu a evolução das variáveis de desenvolvimento nos estados brasileiros entre 19952014? O objetivo central é analisar o comportamento das variáveis individuais de desenvolvimento dos estados brasileiros no interregno de 1995 a 2014.

$\mathrm{O}$ estudo está subdividido em quatro seções além desta introdutória. $\mathrm{Na}$ seção um, encontra-se o referencial teórico sobre a evolução do conceito e das medidas de desenvolvimento. A seção dois descreve a metodologia adotada. Em seguida (seção três), tem-se a análise de resultados. Por fim, na quarta e última seção encontram-se as considerações finais acerca do problema de pesquisa.

\section{Do crescimento de renda ao bem-estar social: evolução dos conceitos e das medidas de desenvolvimento}

A definição de desenvolvimento, ainda que bastante difundida, é alvo de intensos embates acadêmicos e políticos. Feijó (2007) argumenta que a teoria clássica atribui uma fórmula para o crescimento (e automático desenvolvimento) das nações. Sob esta perspectiva, os países pobres devem poupar e investir mais, controlar a explosão demográfica e cuidar de seu povo (saúde, educação, entre outros) a fim de que talentos individuais sejam potencializados.

Rostow (1960), autor clássico das Ciências Econômicas, estabelece cinco estágios para o desenvolvimento. Num primeiro momento, a sociedade estará embasada em um modelo tradicional onde o nível de produção é limitado e sem 
excedentes. Posteriormente, inicia-se o processo de mudança estrutural a fim de colher os frutos da ciência moderna (este estágio é denominado "pré condição para o take off'). No "take off' propriamente dito, a resistência a via do crescimento econômico estão superadas, de tal forma que os hábitos e estruturas institucionais consolidam-se em busca da industrialização como via do crescimento e desenvolvimento econômico.

No estágio "marcha para maturidade", Rostow (1960) afirma que há uma melhora na indústria em termos técnicos: as antigas indústrias se estabilizam e as novas aceleram. A sociedade, então, se adequada totalmente ao modelo moderno em prol do crescimento econômico. Por fim, no quinto e último estágio, denominado alto consumo em massa, a população aufere melhores empregos em razão da expansão industrial. Além disto, a proporção de trabalhos com maiores qualificações aumenta fazendo com que grande parte da população receba renda suficiente para seu consumo básico, como abrigo, comida e vestuário. Através dessa abordagem, dar-se-ia o desenvolvimento automático pela via do crescimento industrial.

O modelo de Rostow foi alvo de inúmeras críticas, sobretudo por sugerir que os países subdesenvolvidos chegariam ao desenvolvimento através da mesma trajetória de modernização das economias desenvolvidas pós Segunda Guerra Mundial. Ou seja, Rostow ditou uma receita a ser seguida para alcançar o desenvolvimento como um modelo atemporal aplicável a qualquer situação e lugar, desprezando suas particularidades geográficas, institucionais, políticas e sociais (CONCEIÇÃO; OLIVEIRA; SOUZA, 2016).

Os críticos dessa versão afirmam que este diagnóstico não é legítimo ao considerar a complexidade da realidade social dos países. Sobretudo, a abordagem sugere como necessidade a forte intervenção do Estado nacional no processo econômico, caso contrário, a nação pobre perpetuará esta condição e haverá tendência ao aumento do abismo que a separa da nação rica (FElJÓ, 2007, p. 3).

Celso Furtado, autor cepalino, destaca a necessidade de construção de uma teoria que considere as peculiaridades históricas de formação social dos países periféricos. Segundo Furtado (1992, p. 7) "A teoria do subdesenvolvimento cuida do caso especial de processos sociais em que aumentos da produtividade e assimilação de novas técnicas não conduzem a homologação social, ainda que induzam à elevação no nível de renda média da população". Em outras palavras, a via do aumento da produtividade não é condição suficiente para que se produza o verdadeiro desenvolvimento (FURTADO, 1992 p. 10). 
Furtado (1992) considera que o crescimento econômico pode ser ferramenta importante pra se alcançar o desenvolvimento, porém não é trajetória suficiente nem mesmo central no processo de desenvolvimento. Desta forma, para gerar desenvolvimento é necessário gerar mudanças no âmbito social e um crescimento administrado que leve ao aumento da qualidade de vida (CASSOL; NIEDERLE, 2016).

Diferentemente do que acreditava Rostow (1960), de que a modernização geraria automaticamente o desenvolvimento, Furtado (1994) crê que essa relação não é direta e aplicável aos países periféricos. Segundo o autor, enquanto nas economias do centro a acumulação conduziu à elevação dos salários reais (devido a escassez de mão de obra) e homogeneização social, na periferia a acumulação engendrava o subemprego e reforçava estruturas tradicionais de dominação.

Destaca-se que Furtado (2004) é ciente que não existe desenvolvimento sem acumulação e avanço técnico, que dão-ser-ia através da industrialização. Porém, para o autor, a industrialização capaz de gerar o verdadeiro desenvolvimento é fruto da realização de um projeto político. Nas palavras do autor: "o processo de desenvolvimento econômico e social não resultam de uma evolução automática e inercial, mas de opção política orientada" (FURTADO, 2004, p. 484).

Assim, as primeiras ações em direção à superação do subdesenvolvimento, segundo Furtado (1994; 2004), não consistem nos processos de acumulação e aumento da produtividade macroeconômica propriamente dita, mas encontram-se nas mudanças necessárias a serem realizas na esfera social e que são aptas a responder às aspirações da coletividade.

O crescimento econômico, tal qual o conhecemos, vem se fundando na preservação dos privilégios das elites que satisfazem seu afã de modernização; já o desenvolvimento se caracteriza pelo seu projeto social subjacente. Dispor de recursos para investir está longe de ser condição suficiente para preparar um melhor futuro para a massa da população. Mas quando o projeto social prioriza a efetiva melhoria das condições de vida dessa população, o crescimento se metamorfoseia em desenvolvimento (FURTADO, 2004, p. 484).

Em perspectiva correlata, Amartya Sen (2010) enfatiza que a trajetória para o desenvolvimento deve se dar com a expansão das liberdades econômicas, sociais e políticas. Desta forma, vê-se que o crescimento não é via suficiente para o desenvolvimento, necessitando de reformas mais profundas, inclusive no âmbito político e social. Em suma, tanto Furtado quando Sen destacam que o 
desenvolvimento dos países subdesenvolvidos deve dar-se por mudanças estruturais, sociais e políticas, devendo considerar as particularidades de cada país.

Outra questão relevante a se apontar tem relação com as metodologias de avaliação/mensuração do desenvolvimento. Em síntese, não rara vezes, costuma-se realizar a comparação entre as estatísticas nacionais, associando-se desenvolvimento econômico ao desempenho do Produto Interno Bruto, isto é, associando o desenvolvimento à via do crescimento econômico. Entretanto, desde a publicação do primeiro Relatório sobre Desenvolvimento Humano, elaborado pelo Programa das Nações Unidas para o Desenvolvimento (PNUD, 1990), a comunidade científica alerta que o Produto Interno Bruto é indicador insuficiente para avaliar o desenvolvimento (KAGEYAMA, 2004).

Sen (1997, p. 385-386) atribui algumas razões da ineficiência do emprego da variável renda como indicador do nível de desenvolvimento, razões estas denominadas "variações paramétricas", a saber: i) heterogeneidades pessoais, como idade, gênero ou presença de doença; ii) diversidades ambientais, que dizem respeito às circunstâncias climáticas, tais como temperatura, chuva, alagamentos e todos os tipos de fenômenos da natureza.; iii) condições sociais que incluem saúde pública, educação pública e nível de criminalidade. ; iv) diferenças de perspectivas refere-se ao meio que o individuo está inserido como, por exemplo, uma sociedade rica ou pobre e v) distribuição da renda familiar entre os indivíduos pertencentes a mesma família.

Em síntese, Sen (2010) afirma que a confusão que ocorre em considerar a renda como indicador do desenvolvimento é a mesma que ocorre entre a diferenciação dos meios e dos fins. Em termos, considera-se que o objetivo fim para o desenvolvimento não é a obtenção de maior renda à população, mas sim a remoção das principais fontes de privação, tais como a pobreza e tirania, a carência de oportunidade econômica, a negligência dos serviços públicos, entre outros fatores que inferem diretamente no bem-estar da vida da sociedade. Assim, o Produto Interno Bruto é apenas um meio para se obter essas capacitações e não o verdadeiro fim para alcançar o desenvolvimento.

Amartya Sen e Mahbud ul Hag, visando preencher algumas lacunas para captar de forma mais eficaz a complexidade que envolve as variáveis do desenvolvimento humano, desenvolveram o Índice de Desenvolvimento Humano (IDH) em 1993. Desde então, o IDH tornou-se referência na literatura especializada. Este índice é composto por três dimensões básicas: educação, renda e saúde. 
Segundo o Programa das Nações Unidas do Brasil (2017) "o IDH pretende ser uma medida geral e sintética que, apesar de ampliar a perspectiva sobre 0 desenvolvimento humano, não abrange nem esgota todos os aspectos de desenvolvimento".

Ademais, foram surgindo na literatura uma gama de teorias modernas para tentar explicar o fenômeno desenvolvimento, tais como: os modelos de imperfeições do mercado de crédito, economia política e conflitos sociais (CASTRO, 2006, p. 65). De forma breve, exploram-se a seguir cada uma destas teorias modernas.

O modelo de imperfeições do mercado de crédito, segundo De Barros (2000), faz referência à limitação dos investimentos em razão das assimetrias de informação e falhas nas leis institucionais. Em virtude dessas imperfeições, os emprestadores demandam garantias dos tomadores de empréstimos e, como consequência, somente empresários com elevado nível de riqueza são habilitados a financiar seus projetos. Devido à presença de imperfeições no mercado de crédito, existe uma limitação do acesso dos agentes mais pobres à capacidade produtiva da economia e, como efeito, retarda o crescimento de longo prazo (CASTRO, 2006, p. 66).

Já a ideia central do modelo de economia política refere-se à motivação do eleitor mediano nas urnas, que sob uma distribuição desigual de renda aspira por ganhos de curto prazo, favorecendo no processo político os candidatos com aspiração a programas políticos de redistribuição de renda (CASTRO, 2006, p. 70). A consequência disto sob o crescimento econômico, segundo Castro (2006), é a criação de maiores distorções que inibem a apropriação privada dos frutos de acumulação de capital e investimento em longo prazo, reduzindo as taxas de crescimento econômico.

No modelo de conflitos sociais, segundo De Barros (2000), altos níveis de desigualdade geram instabilidades sociopolíticas como, por exemplo, ameaças à estabilidade das instituições políticas e a tendência dos pobres a se envolver na criminalidade. (CASTRO, 2006). Destarte, vem à tona o tema já abordado por Furtado e Sen, que afirmam que as mudanças rumo ao desenvolvimento devem ocorrer, principalmente, na esfera política, social e estrutural.

Objetiva-se neste trabalho fazer uma análise das variáveis de desenvolvimento no Brasil ao longo dos anos 1995-2014. O Programa das Nações Unidas para o Desenvolvimento (2017) alerta para a necessidade de analisar os dados, além da realidade das médias nacionais, pois "Reconhecer essas disparidades é fundamental para fazer com que as políticas (como o Bolsa Família) 
sejam fortalecidas e cheguem aos locais e às pessoas que mais necessitam". É neste contexto que este trabalho se encontra, busca-se analisar o comportamento individual das variáveis de desenvolvimento em cada estado brasileiro, e realizar uma comparação entre os mesmos. Na seção posterior será explanado o método de análise utilizado.

\section{Metodologia}

A presente pesquisa é de natureza descritiva, com abordagem qualitativa. Descritiva por objetivar identificar relações entre as variáveis que explicam o comportamento das variáveis de desenvolvimento ao longo do tempo. Qualitativa, por buscar compreender de forma detalhada a evolução dos dados coletados. A riqueza do estudo qualitativo está em focalizar a realidade de forma complexa e contextualizada (DE ANDRADE; LAKATOS, 2007). Ainda, nesse tipo de estudo busca-se não apenas fazer um relatório de dados pesquisados, mas sim relatar 0 desenvolvimento em caráter interpretativo.

Além disso, tal pesquisa mostra-se como um estudo de caso, tanto por trabalhar com regiões definidas, quanto por estabelecer um recorte temporal, como sugere Gil (2002). Para Yin (2001) esse tipo de pesquisa ganha destaque por buscar conhecer o porquê de uma determinada situação, e da descoberta do que nela há de mais essencial e característico.

A abrangência do trabalho são os estados brasileiros e Distrito Federal. A escolha do local de estudo se deu em grande parte pela reconhecida disparidade social existente entre os estados do Brasil. Já a escolha do período de tempo (19952014) se deu fundamentalmente para observar o comportamento do desenvolvimento durante a disponibilidade de dados existentes ${ }^{3}$.

Para que os objetivos propostos fossem alcançados, elaboraram-se mapas a partir de sete variáveis que representam o desenvolvimento no interregno supracitado. A escolha das variáveis se deu em decorrência do que se vem trabalhando na literatura existente englobando indicadores sociais (Índice de Gini), de renda, capital físico (abertura comercial e investimento) e capital humano (escolaridade, gasto social e taxa de homicídio). Salienta-se que servem como proxy as variáveis: i) anos de estudo para o modelo de crédito imperfeito; ii) taxa de homicídio para o modelo de conflito social e iii) gasto com previdência e assistência

\footnotetext{
${ }^{3} \mathrm{~A}$ intenção da pesquisa era realizar uma análise temporal mais ampla, contudo houve dificuldade na coleta de dados secundários, especialmente para o estado do Tocantins, que foi emancipado em 1988.
} 
social para o modelo de economia política.

As variáveis tiveram como fonte o Instituto de Pesquisa Econômica Aplicada (IPEA), o Ministério da Indústria, Comércio Exterior e Serviços (MDIC) e a Empresa de Pesquisa Energética (EPE), como pode ser observado no Quadro 02.

\section{Quadro 02 - Variáveis selecionadas para análise (por estado do Brasil no período de 1995-2014) e fontes de coleta de informação}

\begin{tabular}{|c|c|c|}
\hline \multicolumn{2}{|c|}{ Dados } & Fonte \\
\hline Desigualdade & Índice de Gini & IPEA \\
\hline Renda & Renda per capita \\
\hline \multirow{5}{*}{ Capital Físico } & $\begin{array}{c}\text { Razão exportação com } \\
\text { importação em relação ao } \\
\text { PIB }\end{array}$ & MDIC; IPEA \\
\cline { 2 - 3 } & $\begin{array}{c}\text { Consumo de Energia } \\
\text { Industrial }\end{array}$ & EPE \\
\hline \multirow{5}{*}{ Capital Humano } & $\begin{array}{c}\text { Média de anos de estudos } \\
\text { da população de 25 anos ou } \\
\text { mais }\end{array}$ & IPEA \\
\cline { 2 - 3 } & $\begin{array}{c}\text { Gasto com assistência e } \\
\text { previdência social }\end{array}$ & IPEA \\
\cline { 2 - 3 } & Taxa de homicídio & IPEA \\
\cline { 2 - 3 } &
\end{tabular}

Fonte: Elaboração própria (2017).

Destaca-se que a variável soma de exportação e importação em relação ao Produto Interno Bruto (PIB), expressa originalmente em dólares, foi transformada para valores em reais, considerando-se a taxa de câmbio nominal. Nesta mesma perspectiva, operou-se com o deflacionamento do PIB. Tanto a taxa de câmbio nominal quando o deflator implícito do PIB tiveram como fonte o Instituto Brasileiro de Geografia e Estatística.

Para transformar os dados estatísticos da variável assistência e previdência social em informações relativas ao número de habitantes de cada região (per capita), operou-se com a razão dos valores absolutos da variável em relação ao número de habitantes. Ressalta-se que os dados estatísticos referentes à variável renda per capita, em valores constantes, foi consultada através do site do Instituto de Economia Aplicada.

Para este fim, optou-se por realizar uma análise espacial, ilustrada por mapas gerados nos softwares Geoda e Qgis, que compreenderá a observação da evolução de cada variável por estado. Para apresentação dos referidos resultados, 
selecionou-se quatro anos, de forma convencional e com intervalos relativamente iguais, a saber, os anos de 1995, 2001, 2007 e 2014.

\section{Análise de resultados}

O painel analisado neste estudo constitui-se de 19 anos e 27 unidades (estados brasileiros e Distrito Federal). Visando melhor apresentar o comportamento individual das variáveis, optou-se pelo instrumento de sistematização gráfica das informações, através da confecção de mapas. Destaca-se que os anos demonstrados nas Figuras (04 a 10) foram escolhidos por convenção. Selecionaram-se quatro anos com intervalos relativamente iguais, a fim de se ter a noção da evolução das variáveis durante o período.

A Figura 04 apresenta o primeiro conjunto de mapas, que descreve 0 comportamento da variável Índice de Gini. Pode-se perceber que, de 1995 a 2014, todos os estados brasileiros, com exceção de Roraima, apresentaram uma tendência de melhoria na desigualdade de renda. No ranking por região, a região Sul foi representante do menor Índice de Gini no Brasil nos anos de 2001 (0,54), 2007 $(0,49)$ e $2014(0,44)$.

Em 1995, a região com menor desigualdade de renda era a região Norte $(0,55)$. Destaca-se que a região Nordeste apresentou os piores valores, nos quatro anos representados, embora a desigualdade tenha decrescido nesta região. Em síntese, em 1995 o Índice de Gini na região Norte era de 0,60; em 2001 era de 0,59; em 2007 era de 0,56 e em 2014 era de 0,50.

Vale destacar que dentre os estados brasileiros, a maior desigualdade em 2014 encontra-se na região Centro-Oeste, a saber, no Distrito Federal $(0,58)$. No outro extremo, tem-se Santa Catarina $(0,42)$, Goiás $(0,44)$ e Paraná $(0,45)$, entendidos aqui como os estados mais igualitários no supracitado ano. 
Figura 04 - Evolução do Índice de Gini por estado brasileiro (1995, 2001, 2007 e 2014)

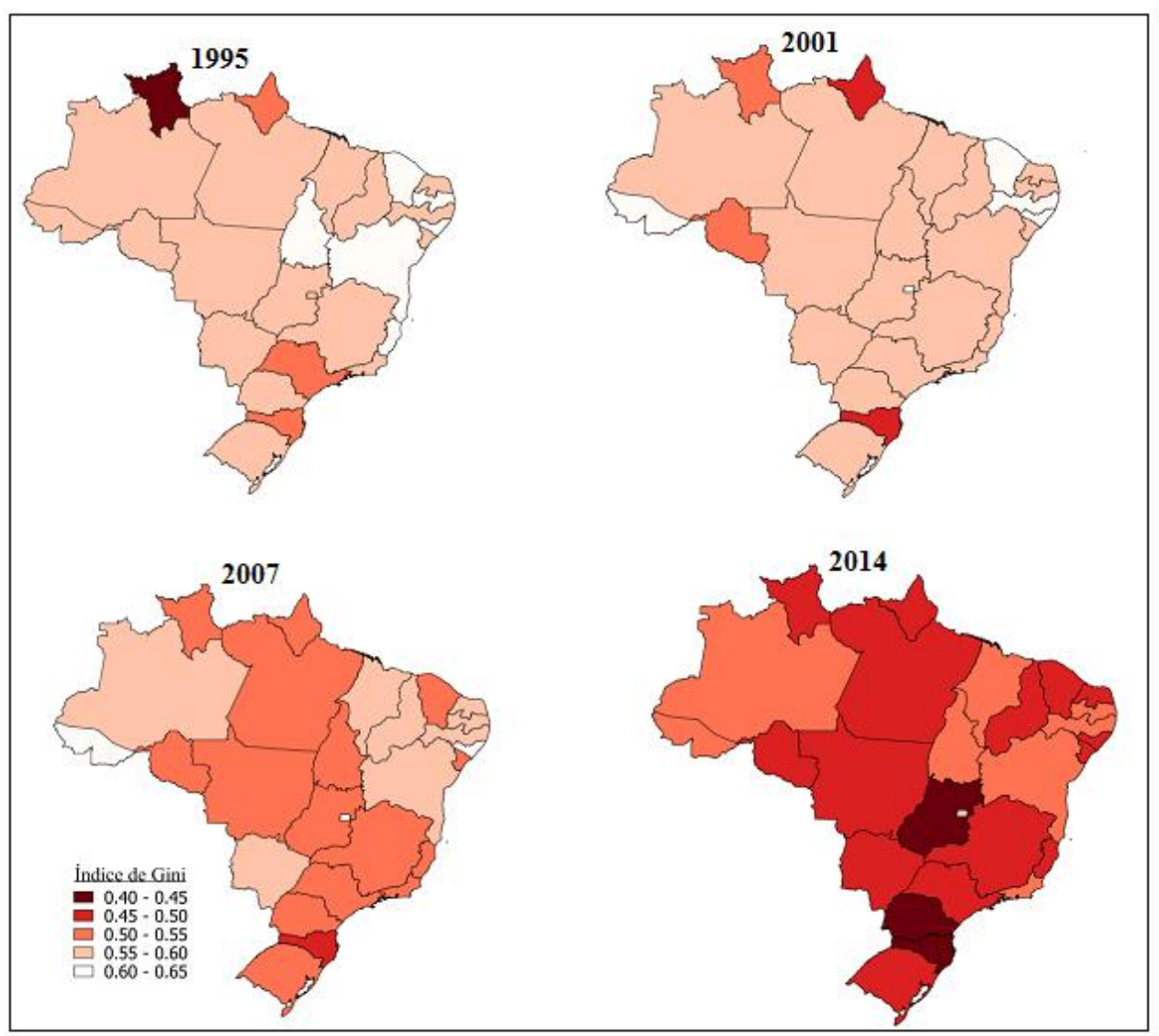

Fonte: Elaboração própria a partir dos softwares Geoda e Qgis.

$\mathrm{Na}$ Figura 05, apresenta-se o comportamento da variável renda per capita. Conforme avaliação dos dados estatísticos, a renda per capita aumentou nos estados brasileiros de 1995 a 2014. Percebe-se que as regiões Sul, Sudeste e Centro-Oeste possuem os melhores resultados em todos os anos. A região Sudeste em 1995 era detentora da maior renda, cerca de $\mathrm{R} \$$ 845,42 per capita. Em 2001 a mesma posição era ocupada pela região Sul, com renda de $R \$ 846,28$.

Todavia, em 2007 e 2014, a região Centro-Oeste foi a que apresentou os melhores resultados em termos de renda per capita $(R \$ 1.057,04$ e $R \$ 1.485,64$, respectivamente). Destaca-se que a pior posição nos quatro anos foi ocupada pela região Nordeste, com renda per capita de $\mathrm{R} \$ 389,07$ em 1995; $\mathrm{R} \$ 390,64$ em 2001; $R \$ 502,75$ em 2007 e $R \$ 714,44$ em 2014.

No ano de 2014, as regiões de renda inferior à brasileira eram: região Norte $(\mathrm{R} \$ 787,76)$ e Nordeste $(\mathrm{R} \$ 730,24)$. Ademais, as regiões com média de renda superior à brasileira eram: a região Centro-Oeste $(R \$ 1.394,40)$, Sudeste $(R \$ 1.378$, 
32) e Sul ( $R \$ 1.413,81)$. Vê-se, assim, uma perpetuação das condições precárias em termos de renda da região Norte e Nordeste. Em 2014, estas mesmas regiões ainda possuíam renda per capita inferior quando comparadas à região Centro-Oeste, Sul e Sudeste de treze anos atrás (a considerar a análise para o ano de 2001). De forma contrária, o Distrito Federal $(\mathrm{R} \$ 2.279,70)$ e os estados de Santa Catarina $(\mathrm{R} \$$ $1.503,32)$ e São Paulo $(R \$ 1.497,76)$ eram detentores das maiores rendas per capita em 2014; ao passo que Alagoas ( $R \$ 592,98)$, Maranhão $(R \$ 614,20)$ e Pará $R \$$ $(676,49)$ destacam-se pela renda per capita mais baixa.

$\mathrm{Na}$ Figura 06 é possível observar que ocorreram algumas mudanças na dinâmica da abertura comercial dos estados brasileiros no decorrer do período analisado. Em 1995, a região Norte $(R \$ 457,02)$ e Sudeste $(R \$ 223,96)$ se destacavam como os mercados com maior volume de comércio com o resto do mundo, em razão dos PIB regionais. No caso específico da região Norte, destaca-se o desempenho do estado de Roraima, que detinha 2.246,268 como valor da razão da soma de exportação e importação em relação ao PIB.

Figura 05 - Evolução da Renda per capita por estado brasileiro (1995, 2001, 2007 e 2014)

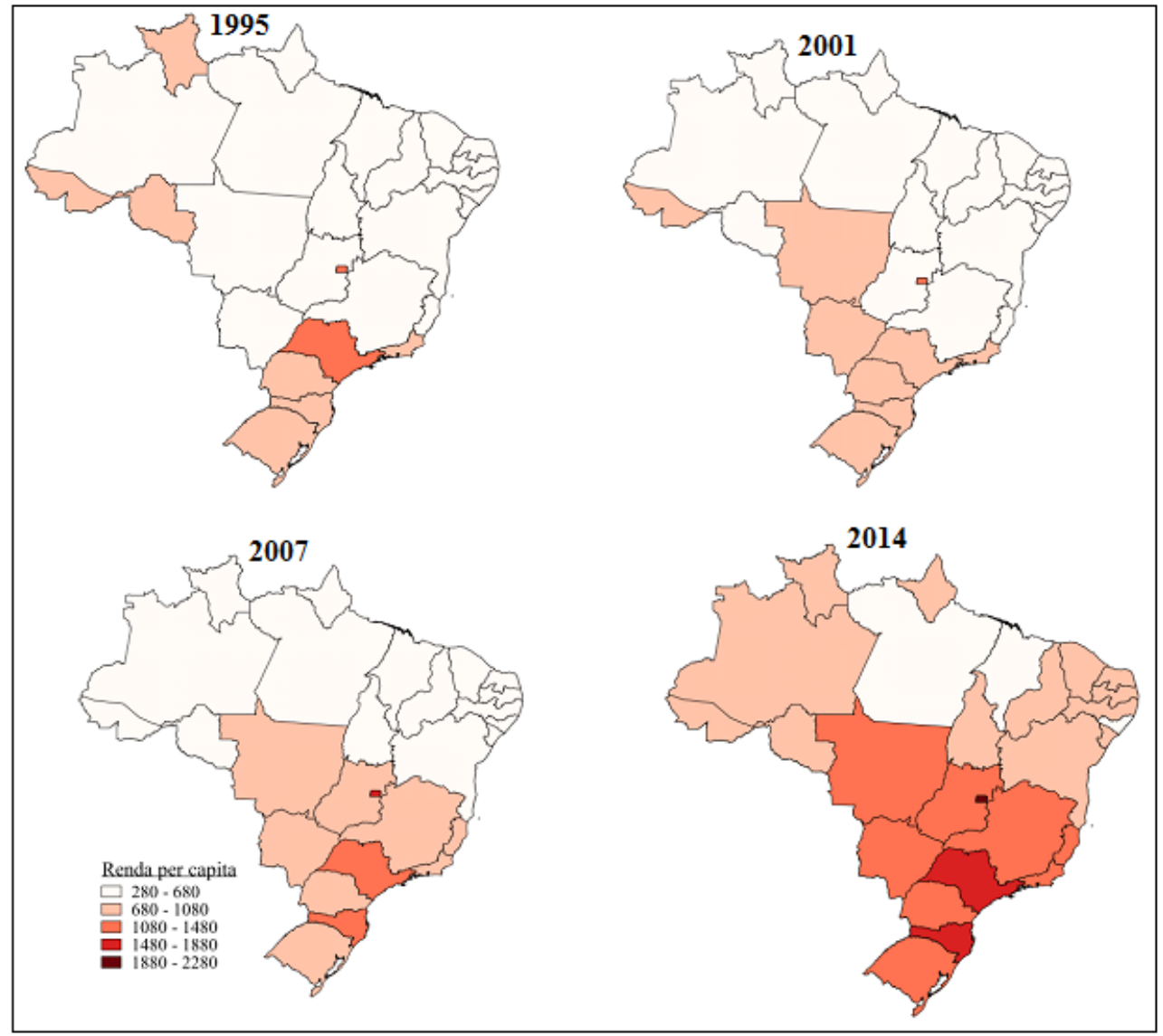

Fonte: Elaboração própria a partir dos softwares Geoda e Qgis. 
Em 2001, a região Norte $(R \$ 151,91)$ encontrava-se em terceiro lugar como a região mais aberta comercialmente, atrás somente da região Sul ( $R \$ 300,37)$ e Sudeste ( $R \$ 297,08)$. Em 2007, as regiões Sul $(R \$ 240,13)$ e Sudeste $(R \$ 229,04)$ continuam como as regiões de maiores aberturas comerciais, porém a região Norte $(R \$ 114,85)$ passa para quarto lugar, atrás da região Centro-Oeste $(R \$ 159,05)$. No ano de 2014 o mercado de maior abertura comercial era a região Sul $(230,41)$, seguido dela região Centro-Oeste $(R \$ 219,81)$, Sudeste $(R \$ 217,30)$, Norte ( $R \$$ $140,90)$ e Nordeste (R\$98,72). É interessante observar que em todos os anos a região Nordeste foi o de menor abertura.

Vale lembrar que a razão entre exportação e importação em relação ao PIB é uma proxy para analisar a abertura comercial. Esta é a única variável que possui um caráter dual, isto é, segundo Barreto (2005) e Linhares et al. (2014), ao mesmo tempo que a abertura comercial permite o acesso a tecnologia e ao conhecimento, pode também fazer com que as diferenças salariais entre o trabalho qualificado e não qualificado aumentem.

Figura 06 - Razão entre a soma de exportação e importação em relação ao Produto Interno Bruto por estado brasileiro (1995, 2001, 2007 e 2014)

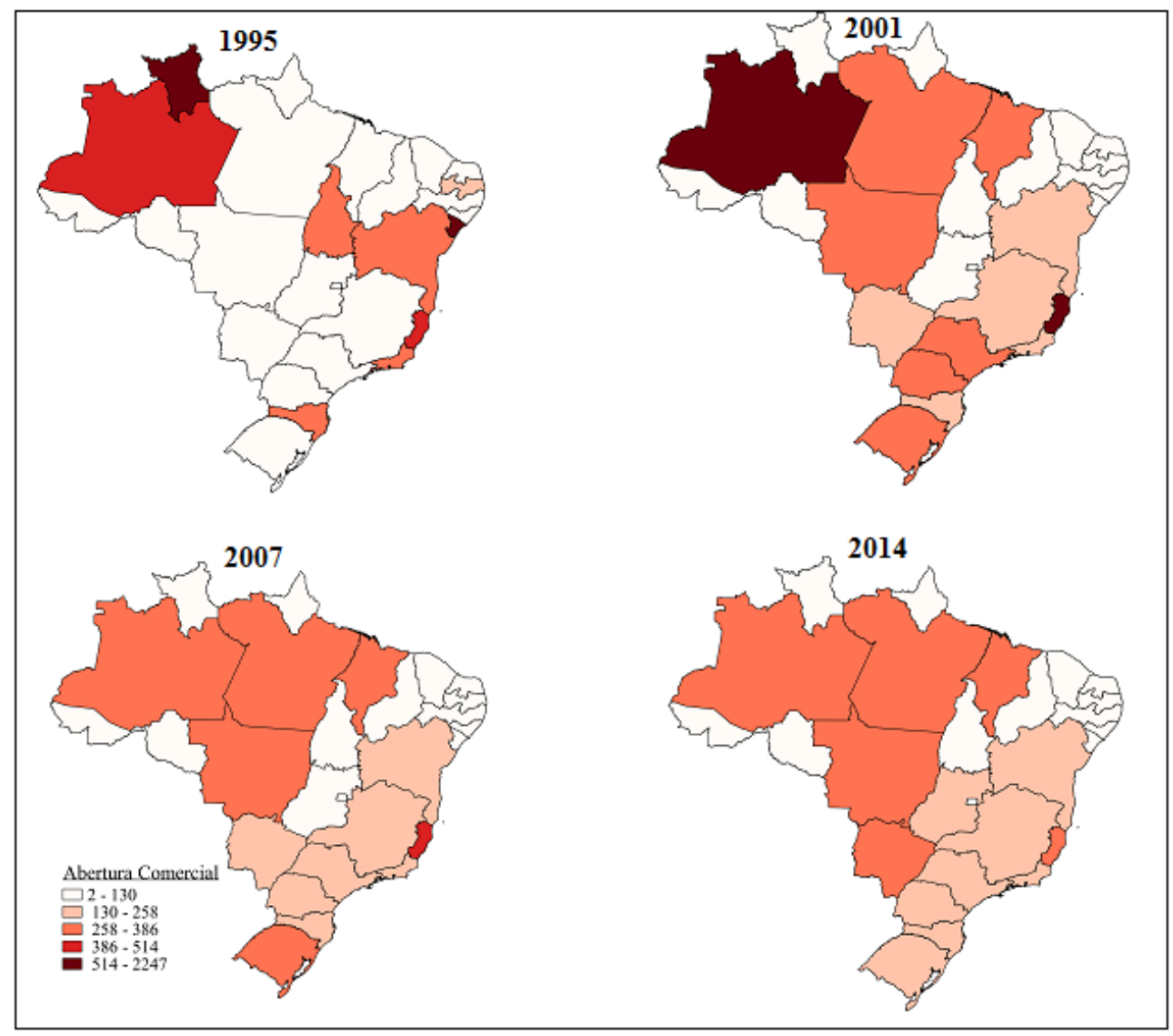

Fonte: Elaboração própria a partir dos softwares Geoda e Qgis. 
A segunda variável, que busca representar a dinâmica do capital físico, é o consumo de energia elétrica industrial, aqui utilizada para avaliar o grau de investimentos dos estados brasileiros. Na Figura 07, é possível observar que a região de maior destaque em todos os quatro anos é a região Sudeste, principalmente em virtude da dinâmica apresentada pelos estados de São Paulo e Minas Gerais. No ano de 2014, outros dois estados se destacam pelo alto gasto de energia elétrica industrial: Paraná e Pará.

Em suma, nos quatro anos de análise a região Sudeste foi a que apresentou maior consumo de energia elétrica industrial, procedida pela região Sul, Nordeste, Norte e Centro-Oeste, com exceção do ano de 2014, em que a região Centro-Oeste encontra-se a frente da região Norte. É importante lembrar que esta variável é uma proxy para o investimento, assim, um maior consumo de energia elétrica industrial significa maior investimento industrial

Figura 07 - Consumo de energia elétrica industrial por estado brasileiro (1995, 2001, 2007 e 2014)

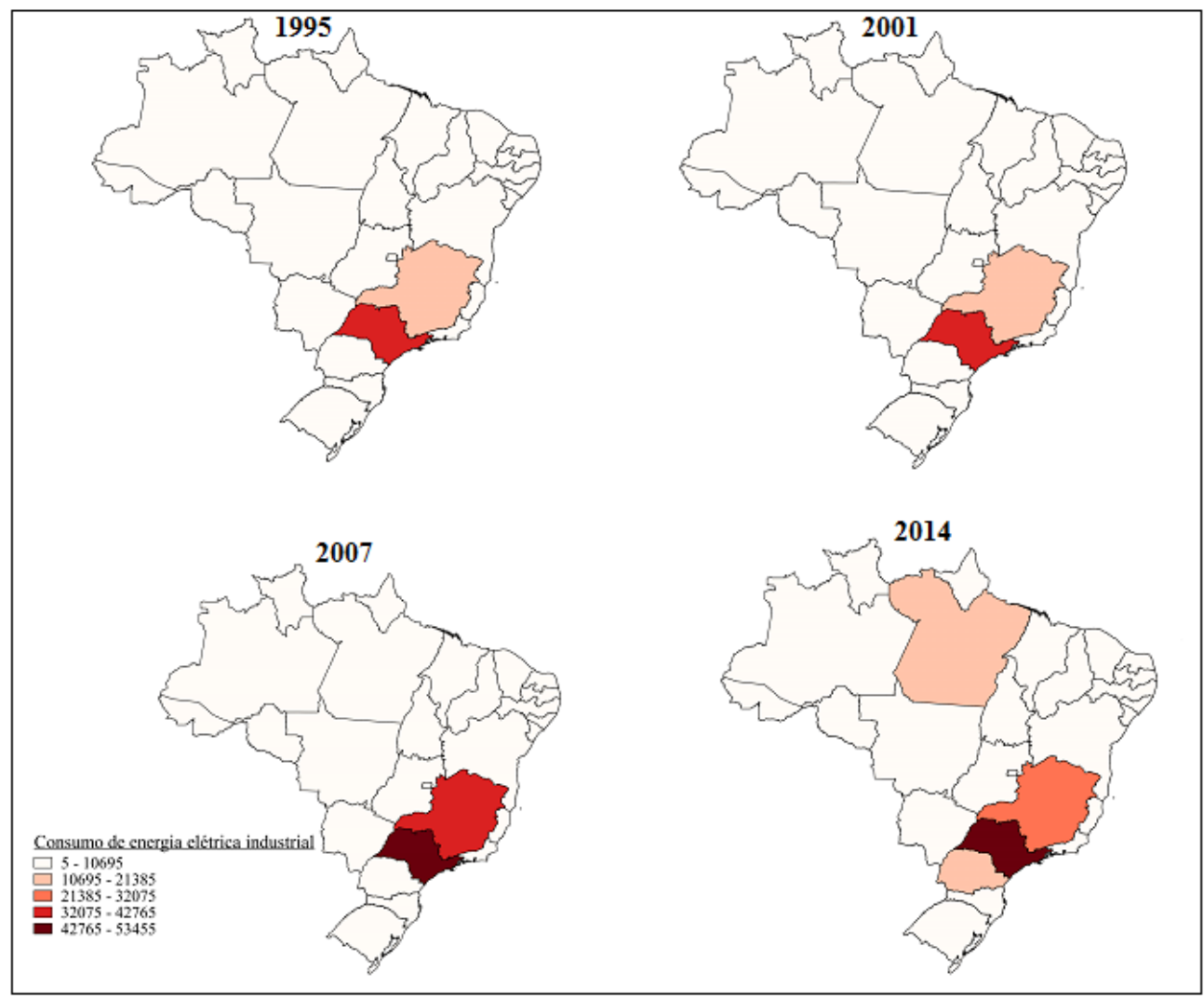

Fonte: Elaboração própria a partir dos softwares Geoda e Qgis. 
O capital humano foi aqui representado por três variáveis. No caso da primeira variável, pautada no modelo de crédito imperfeito, possui como proxy a quantidade de anos de estudos da população de 25 anos ou mais. É importante salientar que diferenças nos anos de estudos individuais levam ao aprofundamento das desigualdades.

A partir da Figura 08 é possível observar que os brasileiros tem apresentado um aumentado de seu nível de educação. Em 1995, 2001 e 2007, a região de maior escolaridade era a Sudeste, com média de 5,7; 6,4 e 7,4 anos de estudos, respectivamente. Já no ano de 2014, a região líder do ranking regional no que tange o acesso ao ensino é a região Centro-oeste, local onde a população apresenta a média de 8,3 anos de estudos. Contribui para o elevado nível de escolaridade da região Centro-oeste o Distrito Federal, local em que os habitantes tem, em média, 10,1 anos de estudos.

O segundo lugar em 1995, 2001 e 2007 era ocupado pela região CentroOeste (com 5,6; 6,3 e 7,2 anos de estudos). Em 2014, a segunda região de maior escolaridade era Sudeste (com média de 8,2 anos de estudo), em razão dos dados para os estados do Rio de Janeiro e São Paulo, que ocupam o segundo e terceiro lugar no ranking dos estados brasileiros com maior escolaridade, ficando atrás somente do Distrito Federal.

Destaca-se que a população da região Sul apresentou a média de 5,5 anos de estudo em 1995; 6,2 anos de estudo em 2001; 7,2 anos de estudo em 2007 e 8,1 anos de estudo em 2014. Ainda, a população da região Norte desempenhou 5,3 anos de estudo em 1995; 5,9 anos de estudo em 2001; 6,5 anos de estudo em 2007 e 7,6 anos de estudo em 2014.

Frisa-se que a população da região Nordeste apresentou 3,8 anos de estudo em 1995; 4,4 anos de estudo em 2001; 5,4 anos de estudo em 2007 e 6,3 anos de estudo em 2014. Salienta-se ainda que em 2014, o Distrito Federal e os estados de Rio de Janeiro e São Paulo são os únicos com média de anos de estudos superiores ao Brasil. Em números, tem-se a média brasileira em 8,79 anos de estudos, enquanto os supracitados estados possuem: 10,1; 8,9; 8,9 anos de estudos, respectivamente. Em contrapartida, os estados de menor escolaridade são Alagoas (com 5,7 anos de estudo) e Piauí (com 5,8 anos de estudo). 
Figura 08 - Média de anos de estudos da população de 25 anos ou mais por estado brasileiro (1995, 2001, 2007 e 2014)

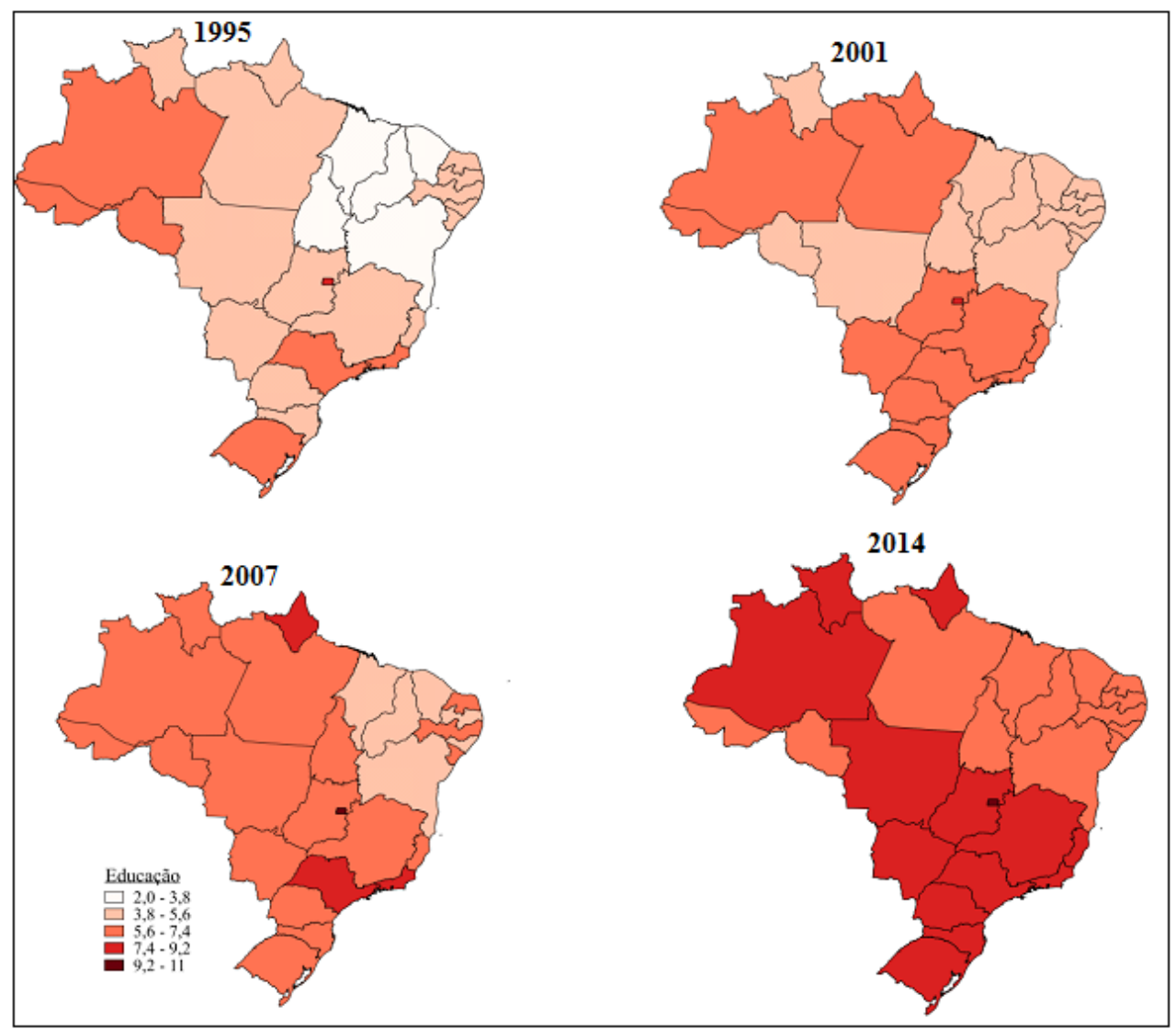

Fonte: Elaboração própria a partir dos softwares Geoda e Qgis.

O segundo indicador utilizado para representar a variável capital humano, pautado no modelo de economia política, tem como proxy o gasto com assistência e previdência social per capita. Ao analisar a Figura 09, percebe-se que houve uma intensificação do gasto social no passar dos anos, principalmente no interregno 2007- 2014. Em 1995 e 2001, o gasto social era maior na região Centro-Oeste, com cerca de $R \$ 131,17$ per capita e $R \$ 266,82$ per capita, nesta ordem.

Em 1995, a região Sul era a segunda maior detentora de gasto social per capita com $R \$ 107,53$; seguido da região Sudeste $(R \$ 87,31)$, Nordeste $(R \$ 36,58)$ e Norte $(\mathrm{R} \$ 35,51)$. Neste mesmo ano, o estado de maior gasto social era Distrito Federal e Rio Grande do Sul. Em 2001, a região que precedia o Centro-Oeste no ranking de gasto social nacional per capita era a região Sudeste $(R \$ 100,08)$, Sul $(R \$ 88,13)$, Nordeste $(R \$ 77,53)$ e Norte $(R \$ 36,54)$, com os estados de maior destaque sendo Espírito Santo e Distrito Federal. 
Figura 09 - Gasto com assistência e previdência social per capita por estado brasileiro (1995, 2001, 2007 e 2014)

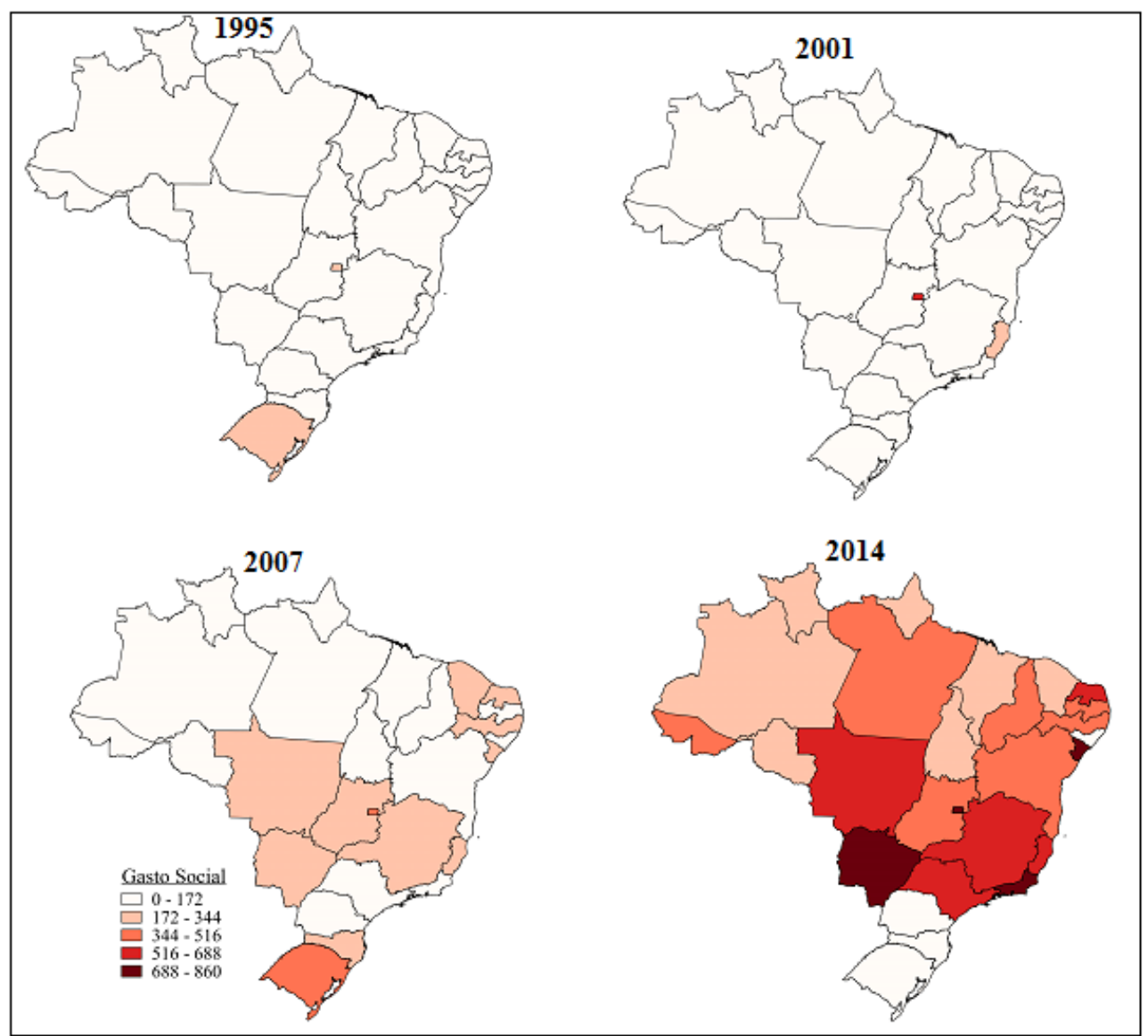

Fonte: Elaboração própria a partir dos softwares Geoda e Qgis.

Em 2007, a região Sul $(R \$ 293,68)$ possuía o maior gasto com assistência e previdência social per capita do Brasil, seguida pela região Centro-Oeste ( $R$ \$ $292,47)$, Sudeste ( $R \$ 203,02)$, Nordeste $(R \$ 168,17)$ e Norte $(R \$ 120,15)$. Percebese que os estados de maiores gastos foram Rio Grande do Sul e Distrito Federal no supracitado ano.

Em 2014, é observada uma expansão significativa do gasto social em todo o Brasil, com exceção da região Sul, que apresentou o menor valor de todos os anos e de todas as regiões observadas, com valor de $R \$ 19,00$ per capita. Ademais, a região Sudeste ( $R \$ 660,43)$ apresentou o maior gasto social de 2014 , seguida pela região Centro-Oeste $(R \$ 605,47)$, Nordeste $(R \$ 392,15)$ e Norte $(R \$ 301,66)$. O maior gasto social em 2014 foi realizado nos estados do Rio de Janeiro, Sergipe, Distrito Federal e Mato Grosso do Sul.

Avalia-se a seguir a taxa de homicídio, aqui entendida como proxy do capital humano, e que tem como intuito agregar à análise os referenciais da teoria moderna de conflito social. Segundo a teoria moderna a maior criminalidade em uma região 
ou estado é indicador de maiores desigualdades, uma vez que esta desigualdade induz os indivíduos ao envolvimento com a criminalidade (cabendo aqui a justificativa da proxy utilizada, taxa de homicídio).

A partir da Figura 10, é possível observar que, de forma geral, houve um aumento da taxa de homicídio na região Norte, Nordeste e Centro-Oeste. Em todos os anos, a região Sul foi representativa da menor taxa de homicídio dentre as regiões brasileiras, com uma média de 13 homicídios a cada 1000 habitantes em 1995; 15 homicídios a cada 1000 habitantes em 2001; 19 homicídios a cada 1000 habitantes em 2007; e 21 homicídios a cada 1000 habitantes em 2014.

Em 1995 e 2001, a região Nordeste ocupava a segunda posição de menor criminalidade do Brasil, com uma média de 15 homicídios a cada 1000 habitantes em 1995 e 21 homicídios a cada 1000 habitantes em 2001. Em 2007, esta mesma região passou a ocupar a terceira posição com média de 28 homicídios a cada 1000 habitantes e, por fim, em 2014 já era considerada a região de maior criminalidade do Brasil, com 42 homicídios a cada 1000 habitantes.

Figura 10 - Taxa de homicídio por estado brasileiro (1995, 2001, 2007 e 2014)

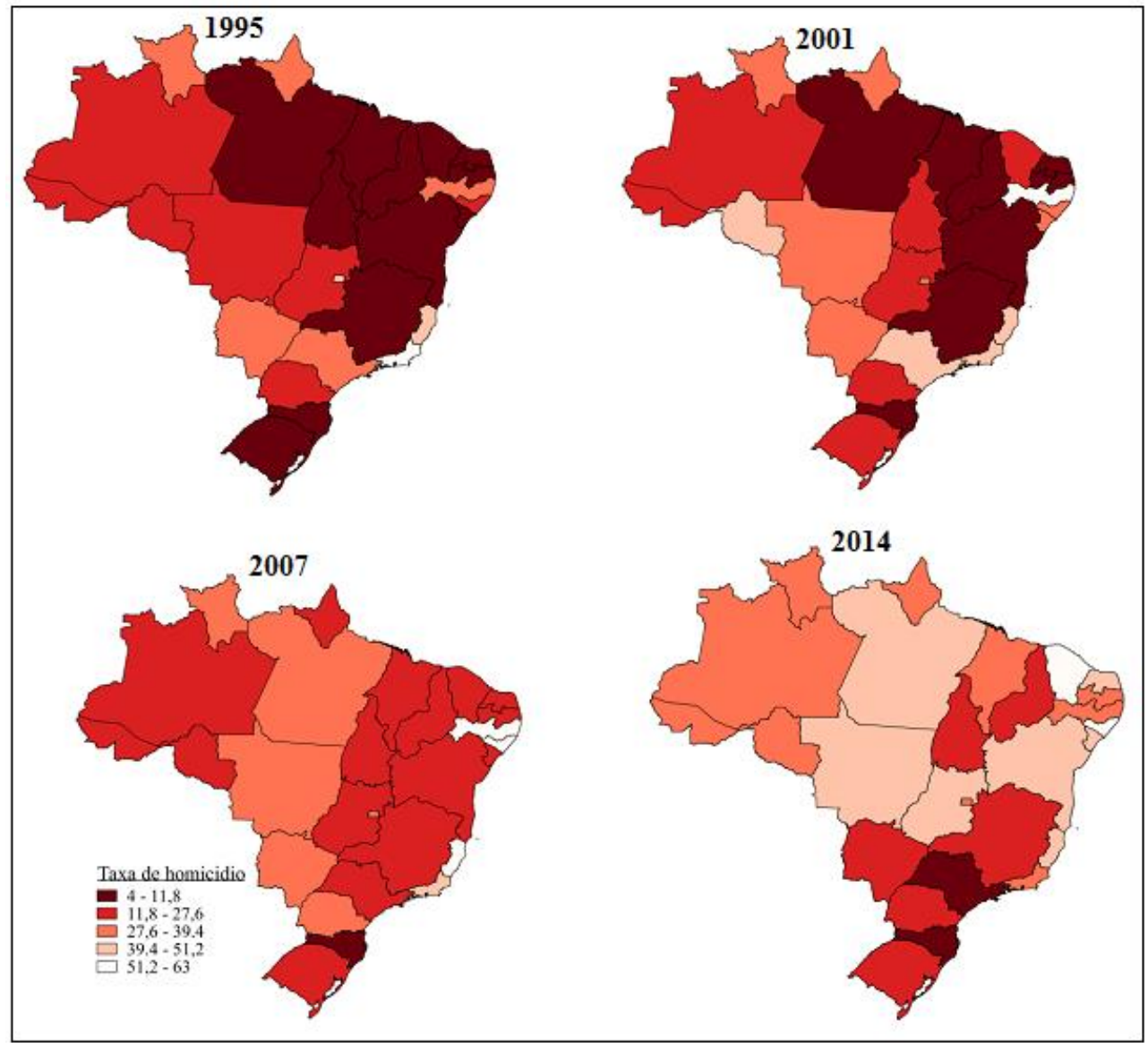

Fonte: Elaboração própria a partir dos softwares Geoda e Qgis. 
A região Norte manteve-se em terceira posição de menor criminalidade em 1995 (22), 2001 (25) e 2014 (32), e em segunda posição de menor criminalidade em 2007 com 32 homicídios a cada 1000 habitantes. A região Centro-Oeste obteve a mesma posição em todos os anos analisados, isto é, a segunda região de maiores quantidades de homicídio, em 1995 com 28 homicídios a cada 1000 habitantes, em 2001 com 31, em 2007 com 29 e em 2014 com 35. Por fim, a região Sudeste foi classificada como a mais perigosa em 1995 com 36 homicídios a cada 1000 habitantes, em 2001 com 37 e em 2007 com 32; já em 2014 foi classificada como a segunda mais segura com uma média de homicídios de 28 a cada 1000 habitantes. Destaca-se que em 2014, o estado do Ceará e Alagoas eram detentores da maior taxa de homicídio; no outro extremo tem os estados de Santa Catarina e São Paulo com as menores taxas de homicídio.

\section{Considerações Finais}

A partir das descrições estatísticas, pode-se concluir que há grande disparidade entre as regiões brasileiras, que são ainda maiores quando considerados os estados. É sabido que o Brasil, um dos maiores países em extensão geográfica do mundo, possui uma ampla diversidade cultural, ambiental e social. Estas diferentes esferas da vida social incorrem em particularidades que, teoricamente, não deveriam ser ignoradas quando na formulação de políticas prol desenvolvimento.

Como principais resultados das análises realizadas, percebe-se que a região Nordeste encontra-se em atraso em comparação às outras regiões em quase todas as variáveis (índice de Gini, renda per capita, média de anos de estudos, abertura comercial e taxa de homicídio), ao passo que a região Sul apresentou três melhores resultados em 2014, a saber, nas variáveis: índice de Gini, taxa de homicídio e abertura comercial. Ainda, a região Sudeste obteve os melhores resultados em 2014 nas variáveis: gasto com assistência e previdência social per capita e consumo de energia elétrica industrial. Também obteve dois melhores resultados a região Centro-Oeste no refere-se à média de anos de estudos e renda per capita.

Destarte, afirma-se que melhoras na educação, um gasto social norteado, aumento do investimento e redução da criminalidade são benéficas e ajudam no desenvolvimento econômico. Neste sentido, acredita-se que a valoração da qualidade de vida da população é algo essencial para redução da desigualdade e da 
pobreza brasileira. Nas palavras do Celso Furtado: "Nunca é demais repetir e insistir que o desenvolvimento se faz para o homem".

\section{REFERÊNCIAS}

BARROS, R. P.; HENRIQUES, R.; MENDONÇA, R.. A Estabilidade inaceitável:

desigualdade e Pobreza no Brasil.Textos para discussão n. 800, IPEA, Rio de Janeiro, p. $1-24,2001$.

BARRETO, F. A. Crescimento econômico, pobreza e desigualdade de renda: o que sabemos sobre eles? Laboratório de Estudos da Pobreza, Fortaleza, p. 1-18, 2005.

BRASIL, Ministério da Indústria, Comércio Exterior e Serviços. Brasília, 2017. Disponível em: http://www.mdic.gov.br/. Acesso em 21 abr. 2017.

BRESSER-PEREIRA, L. C.. Desenvolvimento, progresso e crescimento econômico. Lua Nova, v. 93, p. 33-60, 2014.

CASSOL A.; NIEDERLE P. A. Celso Furtado e a econômica política do desenvolvimento latino-americano. In: NIEDERLE, P. A.; RADOMSKY, G. F. W. (Org.) Introdução às teorias do desenvolvimento. 1 ed. Porto Alegre, 2016. cap 3, p. 29-38.

CASTRO, R. S. Efeitos da desigualdade de renda sobre o crescimento econômico no Brasil: uma análise não linear. 2006. 132 p. Dissertação (Mestrado em Economia) - Universidade Federal do Rio Grande do Sul, Porto Alegre, 2006.

CONCEIÇÃO. A. F.; OLIVEIRA C. G.; SOUZA D. B. Rostow e os Estágios para o Desenvolvimento. In: NIEDERLE, P. A.; RADOMSKY, G. F. W. (Org.) Introdução às teorias do desenvolvimento. 1 ed. Porto Alegre, 2016. cap 1, p. 11-16.

DE ANDRADE M. M.; LAKATOS, E. M. Metodologia do Trabalho Cientifico. $7^{\circ}$ Ed. São Paulo: Atlas, 2007. 228p.

EMPRESA DE PESQUISA ENERGÉTICA.. Disponível em:

http://www.epe.gov.br/Paginas/default.aspx. Acesso em: 21 abr. 2017.

FEIJÓ, R. Desenvolvimento Econômico: Modelos, Evidências, Opções Políticas e o Caso Brasileiro. Editora Atlas S.A, São Paulo, 2007.

FURTADO, C. O subdesenvolvimento revisitado. Revista Economia e Sociedade, Campinas, v. 1, №. 1, 1992.

FURTADO, C. A superação do subdesenvolvimento. Revista Economia e Sociedade, v. 3, $\mathrm{n} \cong$ 1. Campinas, 1994.

FURTADO, C. Os Desafios da Nova Geração. Revista de Economia Política, v.. 24, no 4, Campinas, 2004.

GIL, A. C. Como elaborar projetos de pesquisa. $4^{\circ}$ Ed. São Paulo: Atlas, 2002. 175p.

GRAZIANO DA SILVA, J.. Quem precisa de uma estratégia de desenvolvimento. In: GRAZIANO DA SILVA, J.; MARC, J.; BIANCHINI, V. O Brasil Rural precisa de uma estratégia de desenvolvimento, p. 5-52, 2001.

INSTITUTO BRASILEIRO DE GEOGRAFIA E ESTATÍSTICA. Disponível em: http://www.ibge.gov.br/home/. Acesso: 21 abr. 2017. 
INSTITUTO DE PESQUISA ECONÔMICA APLICADA. Disponível em: http://www.ipeadata.gov.br/Default.aspx. Acesso: 21 abr. 2017

KAGEYAMA, A.. Desenvolvimento Rural: conceito e medida. Brasília: Cadernos de Ciência \& Tecnologia, v. 21, n. 3, p. 379-408, 2004.

LINHARES, F.; FERREIRA, R. T.; IRFFI, G. D.; MACEDO, C. M. B. A hipótese de Kuznets e mudanças na relação entre desigualdade e crescimento de renda no Brasil. Pesquisa e Planejamento Econômico, v. 42, n. 3, 2012.

NIEDERLE, P. A.; RADOMSKY, G. F. W. (Org) Introdução às teorias do desenvolvimento. Editora da UFRGS, 2016.

OLIVEIRA, G. B. de. Uma discussão sobre o conceito de desenvolvimento. Revista da FAE, Curitiba, v.5, n.2, p.41-48, 2002.

PROGRAMA DAS NAÇÕES UNIDAS PARA O DESENVOLVIMENTO. Disponível em: http://www.br.undp.org/content/brazil/pt/home/. Acesso: 18 abr. 2017.

ROSTOW, W. W.. The Stages of Economic Growth: A Non-Communist Manifesto. Cambridge, p. 4-16, 1960.

SEN, A.. From income inequality to economic inequality. Southern Economic Journal, Alabama, v. 64, n. 2, p. 384-401, 1997.

SEN, A.. Desenvolvimento como liberdade. Editora Schwarcz S.A, São Paulo, 2010

SOUZA, N. de J. de. Desenvolvimento econômico. São Paulo: Atlas, 2012, 6 ed.

SUNKEL, O.; PAZ, P.. El sudesarrollo latinoamericano y la teoría del desarrollo. 22. ed. Siglo XX Editores, México, 1988.

VIEIRA, C. A.; ALMEIDA, V. P; OLIVEIRA S. V.; PAULI R. I. P; Desenvolvimento no Rio Grande do Sul 2010/2013: uma perspectiva multidimensional. Anais... Santa Maria: Universidade Federal de Santa Maria, 2017. 55을 Congresso da Sociedade Brasileira de Economia, Administração e Sociologia Rural.

YIN, R. K. Estudo de caso: planejamento e métodos. Trad. de Daniel Grassi. Porto Alegre: Bookman, 2001.

\section{NOTAS DE AUTOR}

\section{CONTRIBUIÇÃO DE AUTORIA}

Cristiéle de Almeida Vieira - Conceituação, Análise formal, Investigação, Aquisição de Financiamento, Metodologia. Escrita- rascunho original

Sibele Vasconcelos de Oliveira - Supervisão. Escrita- revisão e edição, Aquisição de Financiamento, Participação ativa da discussão dos resultados; Revisão e aprovação da versão final do trabalho.

\section{FINANCIAMENTO}

Trabalho apoiado pelo programa de bolsas de pesquisa da Universidade Federal de Santa Maria CSA/CCSH, edital $07 / 2017$. 
APROVAÇÃO DE COMITÊ DE ÉTICA EM PESQUISA

Não se aplica.

CONFLITO DE INTERESSES

Não se aplica.

\section{LICENÇA DE USO}

Este artigo está licenciado sob a Licença Creative Commons CC-BY. Com essa licença você pode compartilhar, adaptar, criar para qualquer fim, desde que atribua a autoria da obra.

\section{HISTÓRICO}

Recebido em: 28-03-2018

Aprovado em: 09-09-2018 